\title{
Existence and Warr Neutrality for Matching Equilibria in a Public Good Economy: An Aggregative Game Approach
}

\author{
Wolfgang Buchholz \\ Richard Cornes \\ Dirk Rübbelke
}

CESIFO WORKING PAPER No. 2884

CATEgory 1: Public Finance

DECEMBER 2009

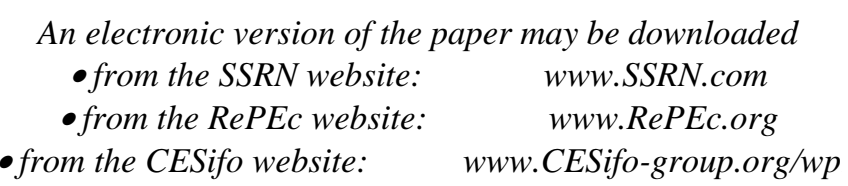




\title{
Existence and Warr Neutrality for Matching Equilibria in a Public Good Economy: An Aggregative Game Approach
}

\begin{abstract}
Using the aggregative game approach as developed by Cornes and Hartley $(2003,2007)$ this paper analyzes the conditions under which matching mechanisms in a public good economy lead to interior matching equilibria in which all agents make strictly positive flat contributions to the public good. In particular we show that the distribution of income among the agents is a crucial determinant for the existence of interior matching equilibria. In addition, we explore which matching mechanisms show Warr neutrality and how the size of the economy affects the possibility of implementing a certain type of Pareto optimal solutions through matching.

JEL Code: H41, H77, Q54.
\end{abstract}

\author{
Wolfgang Buchholz \\ Department of Economics and Econometrics \\ University of Regensburg \\ 93040 Regensburg \\ Germany \\ wolfgang.buchholz@wiwi.uni-regensburg.de
}

Richard Cornes

Economics Program

Research School of Social Sciences

Australian National University

Canberra ACT 0200

Australia

richard.cornes@anu.edu.au
Dirk Rübbelke

CICERO

Pb. 1129 Blindern

0318 Oslo

Norway

dirk.ruebbelke@cicero.uio.no

This Version: December 04, 2009 


\section{Introduction}

Since Pigou (1920) it has become a quite familiar idea in Public Finance to use taxes and subsidies for allocative purposes, i.e., to steer individual behaviour in a welfare-improving way. In the ongoing debate on climate-change policy such mechanisms have been proposed by several authors (see, e.g., Barrett 1990, Falkinger, Hackl and Pruckner 1996, and Nordhaus 2006) to foster international cooperation on the provision of climate protection as an important global public good. In parallel with this literature, a special branch of the theory of voluntary provision of public goods has evolved that analyzes how public good provision may become more efficient by applying some "matching mechanism" under which the public good contributions at least of some agents are subsidized by other agents. In this way, the public good prices that the subsidized agents actually have to pay are lowered, quite similar as in Lindahl's (1919) classical approach, and this change makes them prefer a higher provision level of the public good than in the non-coopertive Nash equilibrium.

Beginning with Guttman (1978, 1987), Roberts (1987, 1992), and Boadway, Pestieau and Wildasin (1989), the theoretical contributions on such subsidy or matching schemes for public goods have been concentrated on the following questions: How are individual incentives to make voluntary contributions to a public good altered by a matching mechanism just when agents look through the veil of the global budget constraint (Falkinger and Brunner 1999)? What subgame perfect matching equilibria will be attained when individuals independently choose their matching rates at the first and then their public good contributions at the second stage of a two-stage game (Danziger and Schnytzer 1991, Althammer and Buchholz 1993, Varian 1994a,b, Boadway, Song and Tremblay 2007)? Which conditions ensure uniqueness of matching equilibria (Andreoni and Bergstrom 1996, Falkinger 1996, Falkinger and Brunner 1999, Kirchsteiger and Puppe 1997)?

One crucial condition, however, has been given little attention. This is the matter of whether matching equilibria can be guaranteed to exist. Only if existence is ensured does further analysis of matching equilibria, such as uniqueness, make sense at all. In the following we therefore will explore the existence issue in a systematic way. To do so, we build on the "aggregative game approach", as newly developed by Cornes and Hartley (2003, 2007), which by now has become an important instrument for the analysis of public good economies. Of special interest in the context of matching are linear matching schemes and, as it is standard in the theory of private provision of a public good, interior solutions where all agents voluntarily choose a strictly positive contribution to the public good. In the literature there is, in contrast to the uniqueness issue, only a rather casual treatment of the existence of interior 
solutions, which, e.g., in Falkinger (1996) and Falkinger and Brunner (1999) is simply assumed. As a consequence it does not become very transparent what the determinants of existence are and when an interior matching equilibrium can be expected. Also the general and abstract existence proof in Bergstrom and Andreoni (1995), which is based on Brouwer's fixed point theorem, does not provide any information on this

Related to existence of an interior matching equilibrium is Warr neutrality (e.g., Warr 1982, 1983, or Cornes and Sandler 1996) which is another central topic in the theory of public goods: If an interior solution is not altered by a small perturbation of the income distribution and thus Warr neutrality applies existence is, for quite trivial reasons, still ensured after such a change of the income distribution. But if Warr neutrality does not hold an interior equilibrium will no longer exist even if the change of the income distribution is very small. We will show in this paper that such a violation of Warr neutrality is not exceptional for matching equilibria but can be excluded by introducing special assumptions for the matching.

In our analysis we will proceed as follows: After describing the framework and characterizing linear matching mechanisms in Section 2, we will in Section 3 use the aggregative game approach (for a summary presentation of this approach also see Cornes 2009) to determine first of all solutions which are candidates for interior matching equilibria. Based on this we show in Section 4 that existence of interior matching equilibria crucially depends on the distribution of initial income among the agents (or in the case of international public goods among countries) and that the conditions for existence are much stricter than in the standard model of voluntary provision of a public good without matching. In Section 5 we then provide a general criterion for local Warr neutrality of a matching mechanism which is equivalent to that for uniqueness of the equilibrium. Thus our analysis sheds new light on the uniqueness issue that is a major topic in the existing literature on matching with public goods. In Section 6 we consider special matching schemes that fulfil this criterion. Among those are on the one hand a cyclical mechanism and on the other a new groupwise mechanism for which there is asymmetric matching between two groups and which may implement the salient Pareto optimal solution where all agents have the same marginal rate of substitution between the private and the public good. In Section 7 we show how increasing the size of the economy by replication affects existence of matching equilibria and, in particular, the suitability of matching schemes to implement specific Pareto-optimal allocations. Section 8 concludes. 


\section{The Framework}

There are $n$ agents ("countries") $i=1, \ldots, N$ with utility functions $u_{i}\left(x_{i}, G\right)$ where $x_{i}$ is private consumption of agent $i$ and $G$ is public good supply. All utility functions are assumed to be twice partially differentiable, strictly monotone increasing in both variables and strictly quasi-concave. In order to avoid the tedious analysis of corner solutions all indifference curves stemming from these preferences are assumed to be tangential to the coordinate axis. Moreover, we suppose that both the private and the public good are strictly normal for any agent $i=1, \ldots, n$. Agent $i$ 's initial private good endowment ("income") is denoted by $w_{i}$. The public good is produced by a summation technology, i.e., $G=\sum_{i=1}^{n} z_{i}$, where $z_{i}=w_{i}-x_{i}$ is agent $i$ 's total contribution to the public good. So we assume that all agents are equally productive in providing the public good and that the thus homogeneous productivity parameter is normalised to $a=1$. But it would also be possible to extend the analysis and some of the results of this paper to public good models where the marginal rate of transformation between the private and the public good may differ between the agents (see, e.g., Cornes and Sandler 1989, Ihori 1996, and Kotchen 2009 for various specifications of such models).

In the case of matching as considered here, $z_{i}$ will consist of two parts: the direct flat contribution $y_{i}$ to the public good chosen by agent $i$ and her indirect contribution that she makes by matching the flat contributions of the other agents $j \neq i$. As borrowing is excluded both components can never become negative, which has in the literature been coined as nobankruptcy condition.

We will restrict attention to linear matching schemes with constant matching rates $\mu_{i j} \geq 0$. The exogenously given parameter $\mu_{i j}$ indicates by how much in terms of own contributions to the public good agent $i$ augments any unit of flat contributions made by some other agent $j \neq i$. The budget constraint of agent $i=1, \ldots, n$ then becomes 


$$
x_{i}+z_{i}=x_{i}+y_{i}+\sum_{\substack{j=1 \\ j \neq i}}^{n} \mu_{i j} y_{j}=w_{i}
$$

which says that agent $i^{\prime} s$ income $w_{i}$ is divided into her private consumption $x_{i}$, her flat contribution $y_{i}$ and her aggregate matching expenses $\sum_{\substack{j=1 \\ j \neq i}}^{n} \mu_{i j} y_{j}$ that are conditional on the other $n-1$ agents' flat contributions $y_{j}$. Whereas eq. (1) looks at agent $i$ 's role as a donor under the given matching mechanism her role as recipient and thus the induced change of her incentive to make contributions to the public good is determined by the aggregate matching rate

$$
\sigma_{i}=\sum_{\substack{j=1 \\ j \neq i}}^{n} \mu_{j i}
$$

which describes how much the other agents add to the flat contribution of agent $i$. The reciprocal value $1 / \sigma_{i}$ then is the marginal rate of transformation between the private and the public good and thus the price agent $i$ has to pay for any additional unit of the public good under the given matching mechanism.

In the literature several tax-transfer mechanisms have been proposed under which agents pay taxes to finance subsidies for public good supply. These mechanisms can, as we will see now, be interpreted as special linear matching schemes. A conceptual difference, however, is that in the tax-transfer approach the action parameter of any agent is not her flat contribution $y_{i}$ as in our matching approach but rather the gross contribution $g_{i}$ that includes the subsidy payments. Thus the relationship between agent $i$ 's gross contribution $g_{i}$ and her net flat contribution is $g_{i}=\left(1+\sigma_{i}\right) y_{i}$ where $\sigma_{i}$ is defined by (2). The most important subsidy schemes are as follows:

(i) The tax-transfer-scheme conceived by Andreoni and Bergstrom (1996) is equivalent to a matching mechanism whose matching rates are given by 


$$
\mu_{i j}^{A B}=\frac{\beta s_{i}}{1-\beta\left(1-s_{j}\right)}
$$

for all $i, j=1, \ldots, N$ with $i \neq j$ where $\sum_{i=1}^{n} s_{i}=1$ and $\beta \in(0,1]$. The parameters $\left(s_{1}, \ldots, s_{n}\right)$ denote the individual agents' tax shares and $\beta$ stands for the rate by which individual contributions $g_{i}$ are subsidized.

(ii) In the subsidy scheme as devised by Falkinger (1996), the whole group of agents $I=\{1, \ldots, n\}$ is divided into distinct $k$ subgroups $I_{1}, \ldots, I_{k}$ of size $n_{1}, \ldots, n_{k}$. Then deviations of the individual contributions $g_{i}$ of some agent $i \in I_{l}$ from the average contribution $\frac{1}{n_{l}-1} \sum_{\substack{j \in I_{l} \\ j \neq i}} g_{j}$ of the other agents in her group $I_{l}$ are rewarded or punished by the rate $\beta>0$. This subsidy scheme boils down to a linear matching mechanism whose matching rates are given by eq. (4) if the subsidized agent $j$ is in the same subgroup $I_{l}$ as agent $i$.

$$
\mu_{i j}^{F}=\frac{\beta}{(1-\beta) n_{l}}
$$

If, however, agents $i$ and $j$ are in different subgroups we have $\mu_{i j}^{F}=0$. Thus the Falkingermechanism is characterized by the properties that matching only occurs within subgroups (and not between them) and that the matching rates are identical for all members of a specific subgroup.

Given any linear matching scheme a Nash equilibrium in which all agents' optimal choices of flat contributions are consistent is defined in the following way.

Definition 1: For a given matching mechanism, given preferences and incomes, an $n$-tuple $\left(y_{1}^{M}, \ldots, y_{n}^{M}\right)$ with $y_{i}^{M} \geq 0$ for all $i=1, \ldots, n$ is a matching equilibrium in flat contributions if for any agent $i=1, \ldots, n$ the flat contribution $y_{i}^{M}$ maximizes utility

$$
u_{i}\left(w_{i}-y_{i}-\sum_{\substack{j=1 \\ j \neq i}}^{n} \mu_{i j} y_{j}, G_{-i}^{M}+\left(1+\sum_{\substack{j=1 \\ j \neq i}}^{n} \mu_{j i}\right) y_{i}\right)
$$

where $G_{-i}^{M}=\sum_{\substack{j=1 \\ j \neq i}}^{n}\left(1+\sum_{k=1}^{n} \mu_{k j}\right) y_{j}^{M}$ denotes public good supply that is generated by the flat contributions of all agents $j \neq i$ and the concomitant matching contributions. 
Just as the existing literature we are primarily interested in interior matching equilibria in which each agent makes a strictly positive flat contribution $y_{i}^{M}>0$. As a next step we will therefore work out those allocations which are the candidates for interior matching equilibria. For this purpose we make use of the aggregative game approach (Cornes and Hartley 2003, 2007) which, as in many other situations of public good provision, considerably facilitates the analysis.

\section{A Characterization of Potential Interior Matching Equilibria}

For any given aggregate matching rate $\sigma_{i}$ attributed to agent $i$ as a recipient let $e_{i}\left(G, 1+\sigma_{i}\right)$ denote agent $i$ 's income expansion path along which agent $i^{\prime} s$ marginal rate of substitution between the private and the public good is equal to $1+\sigma_{i}$. Having strict normality both of the private and the public good, each $e_{i}\left(G, 1+\sigma_{i}\right)$ is defined for all $G>0$ and is strictly increasing in $G$. We then have the following definition that characterizes the candidates for interior matching equilibria through the lens of the aggregative game approach. (For a similar approach in some other context of public good theory see Shrestha and Cheong 2007)

Definition 2: A feasible allocation $\left(\hat{x}_{1}, \ldots, \hat{x}_{n}, \hat{G}\right)$ is called a potential interior matching equilibrium PIME for a given matching mechanism, given preferences and income levels if

$$
\begin{aligned}
& \hat{G}+\sum_{i=1}^{n} e_{i}\left(\hat{G}, 1+\sigma_{i}\right)=\sum_{i=1}^{n} w_{i}=: W \quad \text { and } \\
& \hat{x}_{i}=e_{i}\left(\hat{G}, 1+\sigma_{i}\right) \text { for all } i=1, \ldots, n .
\end{aligned}
$$

Note that for this definition of a PIME it is not essential that agent $i$ 's private consumption $\hat{x}_{i}$ must not exceed her income $w_{i}$. The term PIME is justified by the following result, which provides a necessary condition for interior matching equilibria.

Proposition 1: If, for a given matching mechanism, given preferences and given income levels, the allocation $\left(x_{1}^{M}, \ldots, x_{n}^{M}, G^{M}\right)$ is an interior matching equilibrium, then it must be a PIME.

Proof: By the given matching mechanism agent $i$ 's marginal rate of transformation between the private and the public good is changed to $m r t_{i}=1+\sigma_{i}$. Then, if agent $i$ makes a strictly positive flat contribution in the Nash equilibrium for the given matching scheme, she must 
attain a position where her marginal rate of substitution is equal to this personal marginal rate of transformation, i.e., $m r s_{i}=1+\sigma_{i}$ holds. From the definition of income expansion paths, it then directly follows that eq. (6) is fulfilled for any agent $i=1, \ldots, n$ that makes a strictly positive flat contribution. Since the total income $W:=\sum_{i=1}^{n} w_{i}$ being available in the economy is either used for private consumption or provision of the public good, we have $\hat{G}+\sum_{i=1}^{n} \hat{x}_{i}=W$ as the aggregate budget constraint. Inserting (7) then shows that condition (6) is fulfilled. QED

Under standard assumptions on preferences, existence and uniqueness of a PIME is always ensured which is shown by the following proposition.

Proposition 2: For a given matching mechanism, given preferences and given income levels the PIME, as described by Definition 2, exists and is unique.

Proof: Because of the strict monotonicity of all income expansion paths (as implication of strict normality) the solution described by Proposition 1 is uniquely determined given the utility functions $u_{i}\left(x_{i}, G\right)$, aggregate income $W$ and the parameters $\mu_{i j}$ of the matching mechanism. Since $e_{i}\left(0,1+\sigma_{i}\right)=0$ for all agents $i$ and $\lim _{G \rightarrow \infty} e_{i}\left(G, 1+\sigma_{i}\right)=\infty$ for at least one agent $i$, such a solution exists for all levels $W$ of aggregate income.

QED

By letting $\mu_{i j}=0$ for all $i, j=1, \ldots, N$ with $i \neq j$, the PIME-concept clearly includes the standard interior Nash equilibrium of voluntary provision of a public good without matching (see Cornes and Sandler 1985, 1996, and Bergstrom, Blume and Varian 1986) as a special case. It is also easy to see when a PIME gives a Pareto-optimal solution.

Proposition 3: A PIME is Pareto-optimal if and only if

$$
\sum_{i=1}^{n} \frac{1}{1+\sigma_{i}}=1
$$

Proof: As in an interior matching equilibrium $m r s_{i}=1+\sigma_{i}$ holds for any agent $i$ 's marginal rate of substitution $\mathrm{mrs}_{i}$ between the private and the public good, the Samuelson condition $\sum_{i=1}^{n} \frac{1}{m r s_{i}}=1$ for Pareto optimality in a public good economy is equivalent to (8).

QED

As a special case we now consider PIMEs in which all agents are treated symmetrically in the sense that each receives the same aggregate matching rate $\sigma$, i.e., $\sigma_{i}=\sigma$ holds for each 
agent $i$. Then the efficiency condition (8) translates into $\frac{n}{1+\sigma}=1$ or $\sigma=n-1$, which in particular is obtained if $\mu_{i j}=1$ for all $i, j=1, \ldots, n$ with $i \neq j$. Then, each agent augments some flat contribution of any other agent by the same amount.

Based on the characterization given by Proposition 1 it is now also possible to do some comparative statics on PIMEs. In particular, it can be demonstrated in an elementary way that Warr neutrality applies, i.e., that a PIME is invariant to redistribution of initial income.

Proposition 4: (i) If aggregate income is redistributed among agents, public good supply and private consumption of all agents are not changed in a PIME.

(ii) If aggregate income is increased, public good supply and private consumption of each agent $i$ will increase.

(iii) If some matching rate $\sigma_{i j}$ is increased, public good supply and private consumption of all agents except agent $j$ will increase, too. Private consumption of the recipient agent $j$ will fall.

Proof: (i) This assertion directly follows from (6) as this condition only depends on total income $W$ and not on its distribution among the agents.

(ii) By increasing total income and thus the right hand side of eq. (6) the equilibrium positions of all agents shift outwards along their income expansion paths $e_{i}\left(G, 1+\sigma_{i}\right)$ which implies that both total public good supply and private consumption of all agents are increased.

(iii) If $\mu_{i j}$ goes up agent $j^{\prime} s$ personal rate of transformation between the private and the public good is increased to some $1+\sigma_{j}^{\prime}$ such that - by convexity of indifference curves agent $j$ 's income expansion path is shifted inwards, i.e., $e_{j}\left(G, 1+\sigma_{j}^{\prime}\right)<e_{j}\left(G, 1+\sigma_{j}\right)$ for all $G>0$ as depicted in Figure 1 for the case of two agents. 


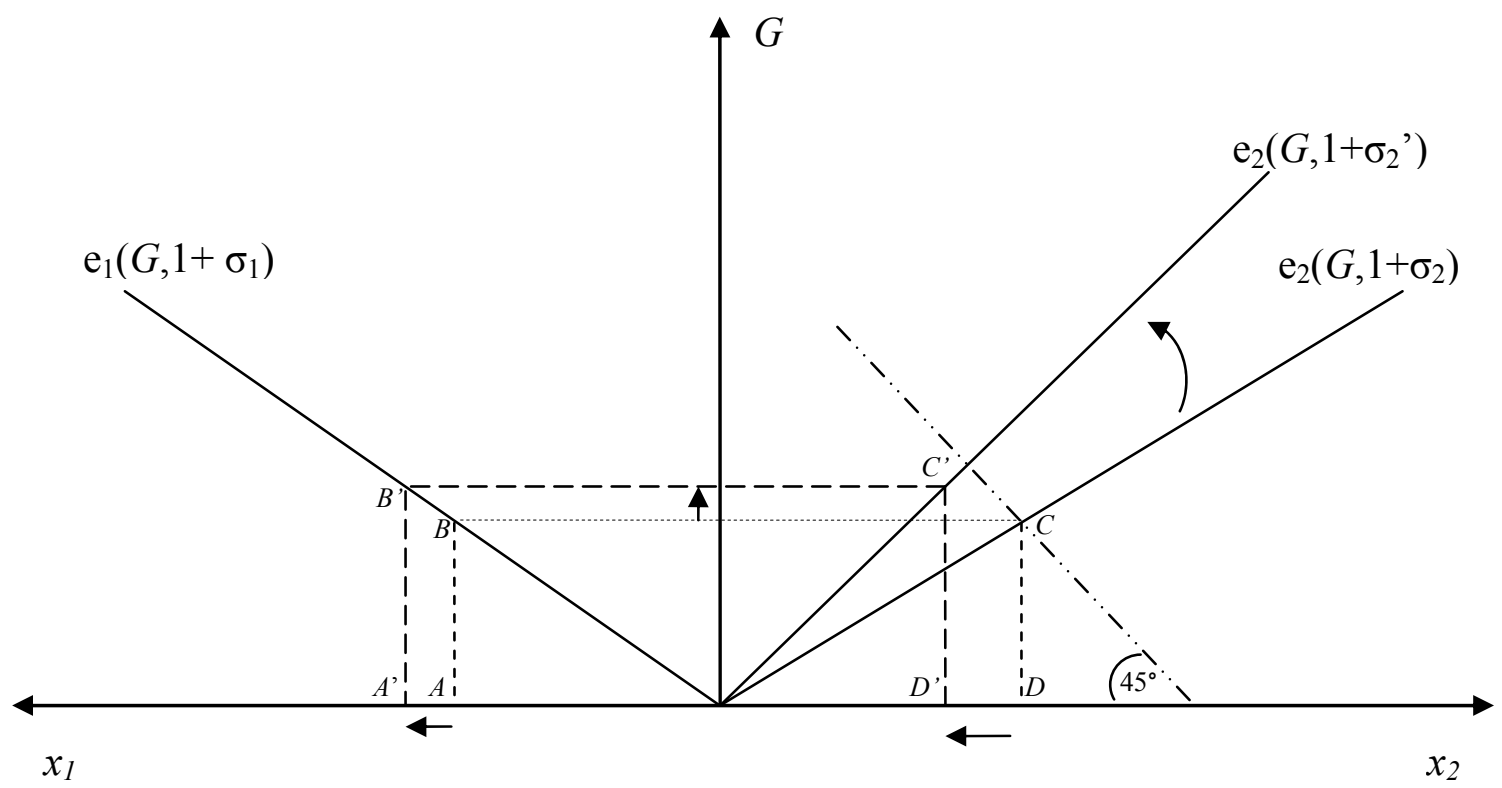

Figure 1: The two-agent case with a rise in one agent's matching rate from $\sigma_{2}$ to $\sigma_{2}$ '.

Then at $\hat{G}$ which is the level of public good supply in the original matching equilibrium we have

$$
\hat{G}+\sum_{\substack{k=1 \\ k \neq j}}^{n} e_{k}\left(\hat{G}, 1+\sigma_{k}\right)+e_{j}\left(\hat{G}, 1+\sigma_{j}^{\prime}\right)<\hat{G}+\sum_{k=1}^{n} e_{k}\left(\hat{G}, 1+\sigma_{k}\right)=W .
$$

Because each income expansion path is strictly increasing in $G$, public good supply must increase to restore equality in (9). Therefore, $\hat{G}^{\prime}>\hat{G}$ holds for public good supply $\hat{G}^{\prime}$ in the new matching equilibrium. This further gives $\hat{x}_{k}^{\prime}=e_{k}\left(\hat{G}^{\prime}, 1+s_{k}\right)>e_{k}\left(\hat{G}, 1+s_{k}\right)=\hat{x}_{k}$ for the levels of private consumptions of all agents $k \neq j$. As the aggregate income $W$ is assumed to be constant here and public good supply as well as private consumption of all other agents increase, private consumption of agent $j$ must definitely fall.

QED

After having described PIMEs as candidates for interior matching equilibria we will now explore the conditions under which a PIME emerges as the true interior matching equilibrium in a certain situation. 


\section{Distribution of Income and the Existence of Interior Matching Equilibria}

From the standard theory of private provision of a public good it is well known (see already Bergstrom, Blume and Varian 1986) that an interior Nash equilibrium with strictly positive contributions of all agents is only obtained when total income is distributed in a certain way. It is an important merit of the aggregative game approach that it directly provides a necessary and sufficient condition on the income distributions required for that: Consider the PIME for the case $\mu_{i j}=0$ for all $i, j=1, \ldots, n$ and $i \neq j$, which gives the standard interior Nash equilibrium without matching. Then, if $\hat{x}_{i}<w_{i}$ holds for the given income distribution $w_{1}, \ldots, w_{n}$ and any agent $i=1, \ldots, n$, the Nash equilibrium $\left(x_{1}^{N}, \ldots, x_{n}^{N}, G^{N}\right)$ of voluntary provision of the public good coincides with the PIME, and it is attained by having $g_{i}^{N}=y_{i}^{N}=w_{i}-\hat{x}_{i}$ as agent $i$ 's contribution to the public good (see Buchholz, Cornes and Peters 2006).

With matching, however, matters become more complicated, and the conditions on the admissible income distributions become more restrictive. This is already seen by looking at a very simple example with two agents that have the same Cobb-Douglas utility function $u_{i}\left(x_{i}, G\right)=x_{i} G$. When $\mu_{12}=\mu_{21}=\mu=1$ the PIME which then is Pareto-optimal is given by $\hat{G}=1$ and $\hat{x}_{1}=\hat{x}_{2}=\frac{1}{2}$ when $W=2$ is assumed. In order to obtain this PIME as the true interior matching equilibrium for some distribution $\left(w_{1}, w_{2}\right)$ of total income $W=2$ among the two agents there must be strictly positive flat contributions $y_{1}$ and $y_{2}$ for which the individual budget constraints

$$
\hat{x}_{i}+y_{i}+\mu y_{j}=\frac{1}{2}+y_{i}+1 \cdot y_{j}=w_{i}
$$

are fulfilled for $i, j=1,2$. This condition, however, demands that income has to be distributed equally, i.e., $w_{1}=w_{2}=1$ holds. Even a small deviation from the symmetric income distribution has the effect that the PIME no longer is the matching equilibrium even if $w_{i}>\hat{x}_{i}=\frac{1}{2}$ still holds for $i=1,2$, i.e., if the conditions that would guarantee the interior solution in the case without matching apply.

With an unequal income distribution the matching equilibrium in our example becomes a corner solution instead: Without loss of generality, we may assume that $w_{1}<w_{2}$. Then in all 
matching equilibria agent 1 makes a zero flat contribution $y_{1}^{M}=0$. If $w_{1}>\frac{w_{2}}{2}$, then agent 2's flat contributions in the matching equilibrium is $y_{2}^{M}=\frac{w_{2}}{2}$ such that public good supply becomes $G^{M}=w_{2}$ and the two private consumption levels are $x_{1}^{M}=w_{1}-\frac{w_{2}}{2}$ and $x_{2}^{M}=\frac{w_{2}}{2}$. In the case $w_{1}<\frac{w_{2}}{2}$ two cases have to be distinguished: If $w_{1} \in\left[\frac{w_{2}}{3}, \frac{w_{2}}{2}\right]$, we get $y_{2}^{M}=w_{1}$ which gives $G^{M}=2 w_{1}$ and $x_{1}^{M}=0$ and $x_{2}^{M}=w_{2}-w_{1}$. If, however, $w_{1}<\frac{w_{2}}{3}$ the flat contribution of agent 2 becomes $y_{2}^{M}=\frac{w_{2}-w_{1}}{2}$. Hence, $G^{M}=x_{2}^{M}=\frac{w_{1}+w_{2}}{2}$ and again $x_{1}^{M}=0$. This is a quite extreme solution since it implies that agent 2, if she is poor enough, will be completely impoverished through the matching mechanism. The determination of such corner solutions is not straightforward, even in this simple case with only two agents. Details of the proof can be obtained from the authors on request. This example shows that, as compared to the standard case of voluntary public good provision without matching, more restrictive conditions characterise income distributions for which an interior matching equilibrium is in fact attained. To facilitate the exposition we introduce the following notations.

Definition 3: For a given matching mechanism, given preferences and given total income $W$,

- Denote by $\Pi$ the set of all income distributions $\left(w_{1}, \ldots, w_{n}\right)$ for which $w_{i}>\hat{x}_{i}=$ private consumption of agent $i$ in PIME for all $i=1, \ldots, n$, and

- Denote by $\Omega$ the set of all income distributions $\left(w_{1}, \ldots, w_{n}\right)$ for which the matching equilibrium coincides with the PIME.

If $\left(w_{1}, \ldots, w_{n}\right) \in \Omega$ we will also say that the PIME is implemented by the given matching mechanism. The sets $\Pi$ and $\Omega$ thus defined are subsets of the simplex $\Lambda(W)=$ $\left\{\vec{w}=\left(w_{1}, \ldots, w_{n}\right): \sum_{i=1}^{n} w_{i}=W\right\}$ which geometrically describes the set of all feasible distributions of total income $W$ among the agents in the $\square^{n}$-space. Clearly, under the no-bankruptcy condition we have $\Omega \subset \Pi$, and the example considered above shows that with matching it is well possible that $\Omega$ is smaller than $\Pi$. The next proposition, which is one of the main results of the paper, provides a criterion that shows which income distributions are in $\Omega$ and which are not. 
Proposition 5: For a given matching scheme, given preferences and given total income $W$, some distribution $\left(w_{1}, \ldots, w_{n}\right) \in \Pi$ is an element of $\Omega$ if and only if the system of the $n$ equations with the $n$ unknowns $y_{1}, \ldots, y_{n}$

$$
y_{i}+\sum_{\substack{j=1 \\ j \neq i}}^{n} \mu_{i j} y_{j}=z_{i}:=w_{i}-\hat{x}_{i} \quad \text { for } i=1, \ldots, n
$$

has a solution $\tilde{y}_{1}, \ldots, \tilde{y}_{n}$ with strictly positive flat contributions $\tilde{y}_{i}>0$ for all agents $i=1, \ldots, n$.

Proof: "Only if": As a consequence of Proposition 1, private consumption of each agent $i=1, \ldots, n$ in an interior matching equilibrium must be equal to its PIME level $\hat{x}_{i}<w_{i}$. If $y_{1}^{M}, \ldots, y_{n}^{M}$ are the agents' flat contributions in the interior matching equilibrium then agent $i^{\prime} s$ budget constraint is

$$
\hat{x}_{i}+y_{i}^{M}+\sum_{\substack{j=1 \\ j \neq i}}^{n} \mu_{i j} y_{j}^{M}=w_{i}
$$

Since (12-i) is identical to (11-i) for any $i=1, \ldots, n$, the system of equations described by (11-i) is solved by $y_{1}^{M}, \ldots, y_{n}^{M}$, which are all strictly positive as an interior solution has been assumed.

"If": Consider an arbitrary agent $i$ and assume that all other agents $j \neq i$ have chosen the flat contributions $\tilde{y}_{j}$ which are the solutions of the equations given by (11-i). Agent $i^{\prime} s$ optimal reaction to the $(n-1)$-tuple of these flat contributions and thus to aggregate public good supply $\tilde{G}_{-i}$ of the other agents then is obtained by maximizing utility

$$
u_{i}\left(w_{i}-y_{i}, \tilde{G}_{-i}+y_{i}+\sum_{\substack{j=1 \\ j \neq i}}^{n} \mu_{j i} \tilde{y}_{j}\right)
$$

Solving this optimization problem, agent $i$ may choose any flat contribution $y_{i}$ in the interval $\left[0, \min _{j \neq i}\left\{\left(w_{j}-\tilde{y}_{j}-\sum_{\substack{k=1 \\ k \neq i, j}}^{n} \mu_{j k} \tilde{y}_{k}\right) / \mu_{j i}\right\}\right]$ since the budget constraints of any agent have to be respected. From the condition given by (11-i) it follows that $y_{i}=\tilde{y}_{i}$ lies in the interior of this interval and thus is an admissible flat contribution for agent $i$. If agent $i$ now actually chooses $y_{i}=\tilde{y}_{i}$ as her flat contribution this (together with the flat contributions $\tilde{y}_{j}$ of the 
agents $j \neq i$ ) gives the level of public good supply $\hat{G}$ as provided in the PIME, which is shown by summing up all $n$ equations (11-i) (since the left hand side of any of these equations gives the total public good contribution of each agent). Then, also from (11-i), it is immediate that agent $i$ by choosing $\tilde{y}_{i}$ as flat contribution, attains her PIME-position $\left(\hat{x}_{i}, \hat{G}\right)$, where her marginal rate of substitution is $\operatorname{mrs}_{i}=1+\sigma_{i}=1+\sum_{\substack{j=1 \\ j \neq i}}^{n} \mu_{j i}$ and thus is equal to her personal marginal rate of transformation under the given matching scheme. This shows that agent $i^{\prime} s$ choice of the flat contribution $\tilde{y}_{i}$ is indeed her best reply when all other agents $j \neq i$ have decided to make the flat contributions $\tilde{y}_{j}$. Since this consideration can be applied to all agents $i=1, \ldots, n$ the "If"-part of the proposition has been proven.

QED

To illustrate how the condition given in Proposition 5 narrows the range of income distributions that yield an interior matching equilibrium we consider the case with two agents $i=1,2$ again but with a general linear matching scheme for which the matching rates are now abbreviated by $\mu_{1}=\mu_{12}$ and $\mu_{2}=\mu_{21}$. The system of equations described by eq. (11-i) then becomes

$$
\begin{aligned}
& y_{1}+\mu_{1} y_{2}=z_{1} \\
& y_{2}+\mu_{2} y_{1}=z_{2}
\end{aligned}
$$

which, if $\mu_{1} \mu_{2} \neq 1$, has the solution

$$
\begin{aligned}
& \tilde{y}_{1}=\frac{z_{1}-\mu_{1} z_{2}}{1-\mu_{1} \mu_{2}} \\
& \tilde{y}_{2}=\frac{z_{2}-\mu_{2} z_{1}}{1-\mu_{1} \mu_{2}} .
\end{aligned}
$$

Combining (15-1) and (15-2) and observing that $\tilde{y}_{1}$ and $\tilde{y}_{2}$ must be strictly positive, an interior matching equilibrium is obtained in the case 1 with $\mu_{1} \mu_{2}<1$, if and only if $z_{1}$ and $z_{2}$ fulfil the following condition

$$
\mu_{2} z_{1}<z_{2}<\frac{z_{1}}{\mu_{1}}
$$

In the case 2 with $\mu_{1} \mu_{2}>1$ the analogous condition is 


$$
\mu_{2} z_{1}>z_{2}>\frac{z_{1}}{\mu_{1}}
$$

Inserting $z_{i}=w_{i}-\hat{x}_{i}$ for $i=1,2$ in the case $\mu_{1} \mu_{2}<1$, the inequalities in (16-1) transform into the following condition that directly refers to income distributions $\left(w_{1}, w_{2}\right)$ :

$$
\hat{x}_{2}+\mu_{2}\left(w_{1}-\hat{x}_{1}\right)<w_{2}<\hat{x}_{2}+\frac{1}{\mu_{1}}\left(w_{1}-\hat{x}_{1}\right) .
$$

The restriction on the income distributions provided by (17) can be visualised in a $w_{1}-w_{2}-$ diagram: So let in Figure $2 \ell_{1}$ be the straight line with slope $\frac{1}{\mu_{1}}$ and $\ell_{2}$ the straight line with slope $\mu_{2}$ both passing through the point $A=\left(\hat{x}_{1}, \hat{x}_{2}\right)$. Then condition (17) means, that the set $\Omega$ of income distributions leading to an interior matching equilibrium is represented by the segment $B C$ whose endpoints are the points of intersection of $\ell_{1}$ and $\ell_{2}$ with the negatively sloped $45^{\circ}$-line of constant total income $w_{1}+w_{2}=W$. Since $\mu_{1} \mu_{2}<1$, the line $\ell_{1}$ lies above $\ell_{2}$ such that the set $\Omega$ is not empty, if $n=2$. It is also obvious from Figure 2 that the segment $D E$, which represents all income distributions that have $\hat{x}_{i}<w_{i}$ for $i=1,2$ and thus the set $\Pi$, is much larger than $B C$.

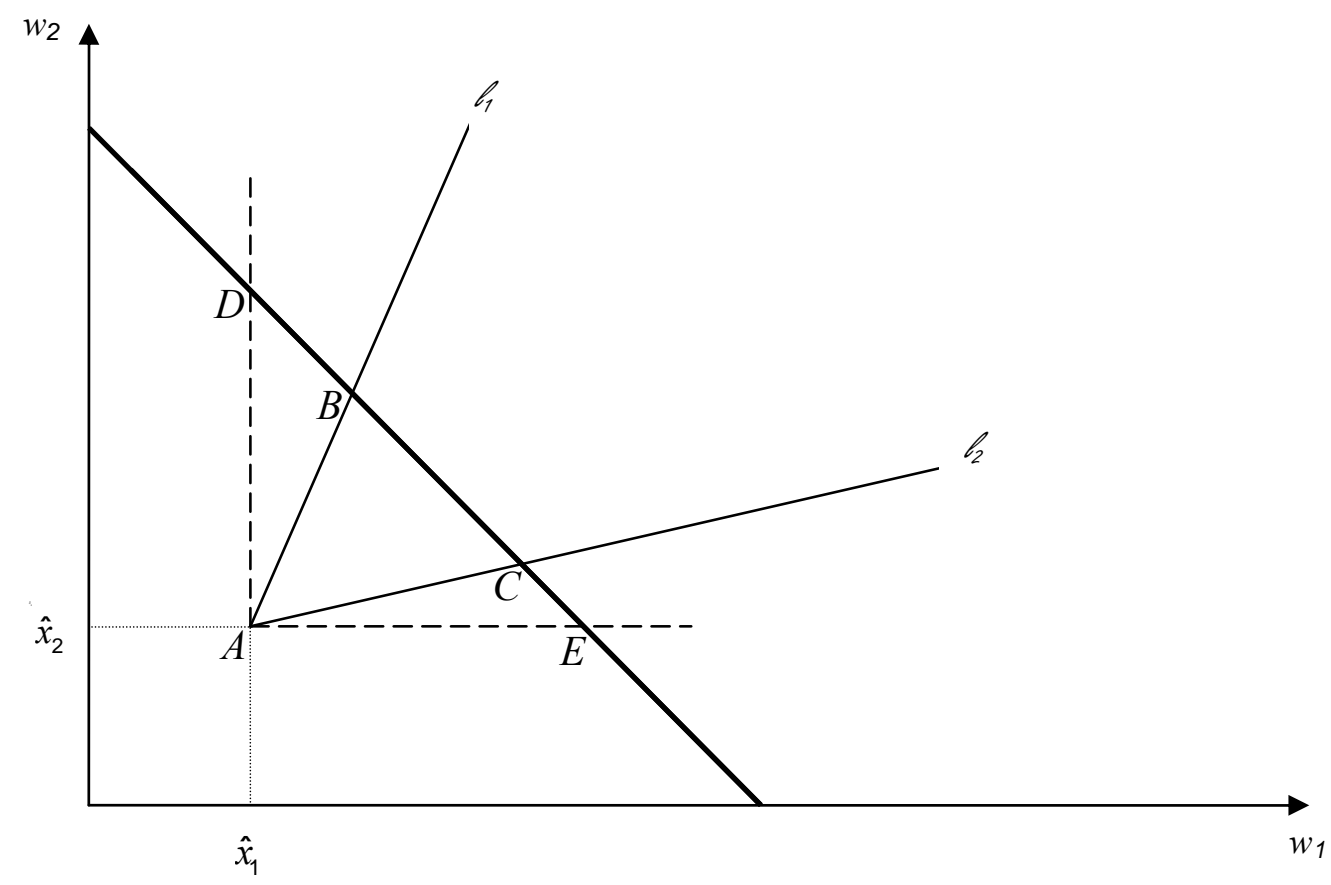

Figure 2: Set of income distributions leading to interior equilibria. 
The case $\mu_{1} \mu_{2}>1$ can be treated by a quite analogous analysis which, however, will be omitted here.

Condition (17) and Figure 2 are helpful for exploring how the set $\Omega$ changes if the matching parameters $\mu_{1}$ and $\mu_{2}$ are varied. In particular we assume that both $\mu_{1}$ and $\mu_{2}$ are increased which implies that $\ell_{1}$ becomes flatter and $\ell_{2}$ becomes steeper. In Figure 2 this implies that the segment $B C$ and therefore the set $\Omega$ will shrink. In the limit, when $\mu_{2}=\frac{1}{\mu_{1}}$ or $\mu_{1} \mu_{2}=1$, the straight lines $\ell_{1}$ and $\ell_{2}$ coincide. Then only one single income distribution is left over for which an interior matching equilibrium is obtained. The case $\mu_{1} \mu_{2}=1$ is of particular interest because this relationship between the two matching parameters is equivalent to $\frac{1}{1+\mu_{1}}+\frac{1}{1+\mu_{2}}=1$ which is the Samuelson rule for the PIME given $\mu_{1}$ and $\mu_{2}$. Therefore, income must be distributed in a very specific way if a Pareto optimal allocation is to be implemented through a matching scheme. This generalizes the result we have reached earlier on for the case $\mu_{1}=\mu_{2}=1$.

So we can conclude that in the case with only two agents it is a rather unlikely eventuality that an efficient solution is obtained through matching since there is exactly one distribution of income for which the expected Pareto-optimal solution is brought about. These extreme demands on the income distribution are completely independent of the underlying preferences.

If there is the possibility that the set $\Omega$ is so small that it only contains a single element one might even suspect that there is no income distribution at all for which an interior matching equilibrium is obtained. But fortunately this is not the case as the following proposition shows.

Proposition 6: For a given matching mechanism, given preferences and given total income $W$ the set $\Omega$ is not empty and contains an income distribution $\left(\breve{w}_{1}, \ldots, \breve{w}_{n}\right)$ with strictly positive components $\breve{w}_{i}>0$ for all $i=1, \ldots, n$.

Proof: Define

$$
\tilde{y}:=\frac{\hat{G}}{n+\sum_{i=1}^{n} \sigma_{i}} .
$$


Then let income $\breve{w}_{i}$ of agent $i=1, \ldots, n$ be

$$
\breve{w}_{i}:=\hat{x}_{i}+\tilde{y}\left(1+\sum_{\substack{j=1 \\ j \neq i}}^{n} \mu_{i j}\right)
$$

Summing up the $\breve{w}_{i}$ 's and observing the definition in (18) and the fact that private consumption of all agents and public good supply must exhaust aggregate income $W$ gives

$$
\sum_{i=1}^{n} \breve{w}_{i}=\sum_{i=1}^{n} \hat{x}_{i}+\tilde{y}\left(n+\sum_{i=1}^{n} \sum_{\substack{j=1 \\ j \neq i}}^{n} \mu_{i j}\right)=\sum_{i=1}^{n} \hat{x}_{i}+\tilde{y}\left(n+\sum_{i=1}^{n} \sigma_{i}\right)=\sum_{i=1}^{n} \hat{x}_{i}+\hat{G}=W
$$

Hence, $\left(\breve{w}_{1}, \ldots, \breve{w}_{n}\right)$ is indeed a distribution of $W$. It directly follows from the construction that $\breve{w}_{i}>0$ holds for any $i=1, \ldots, n$. Finally, the comparison of (20) with (11-i) shows that $y_{i}:=\tilde{y}$ for all $i=1, \ldots, n$ is a solution to the system of linear equations described by (11-i) such that, by Proposition 5, an interior matching equilibrium is obtained for the income distribution $\left(\breve{w}_{1}, \ldots, \breve{w}_{n}\right)$.

QED

Proposition 6 in particular shows that, by an adequate distribution of income, it is always possible to get an interior matching equilibrium in which the flat contributions for all agents are of equal size.

That the existence of interior matching equilibria so strongly depends on income distribution as shown in this section moreover suggests that the range of income redistribution for which Warr neutrality (and other comparative statics properties like those associated with increases of income or matching rates) applies is more limited as in the conventional case of voluntary public good provision without matching. This presumption is confirmed by the analysis in the next section in which the issue of Warr neutrality will be examined more closely.

\section{Local Warr Neutrality for Interior Matching Equilibria: The General Criteria}

Since the seminal work by Bergstrom, Blume and Varian (1986) it is well known that in the standard model of voluntary public good provision, a large income redistribution that changes the group of active contributors to the public good will alter the Nash equilibrium and thus destroy Warr neutrality. Therefore, Warr neutrality from the beginning is a local property of Nash equilibria which by the following definition can be extended to general linear matching mechanisms. 
Definition 4: A linear matching scheme has the local Warr neutrality property for interior matching equilibria and is therefore called a $W$-scheme if and only if - for any given preferences and any given total income $W>0-\left(w_{1}, \ldots, w_{n}\right) \in \Omega$ implies $\left(w_{1}^{\prime}, \ldots, w_{n}^{\prime}\right) \in \Omega$ whenever $\left(w_{1}^{\prime}, \ldots, w_{n}^{\prime}\right)$ is close enough to in the sup-topology, i.e., when $\sup _{i=1, \ldots n}\left|w_{i}^{\prime}-w_{i}\right|<\varepsilon$ for some $\varepsilon>0$.

In the standard situation without matching this property is clearly fulfilled and, moreover, the maximum value for $\varepsilon$ that is admissible according to Definition 4 can easily be determined as $\varepsilon_{\max }=\min _{I=1, \ldots, n}\left\{w_{i}-\hat{x}_{i}\right\}$. With matching, however, it crucially depends on the nature of the given matching mechanism whether local Warr neutrality applies or not. A sufficient and necessary criterion for that is provided by the following Proposition. As a preparation for this result we introduce the transformation matrix $M$ that is defined by

$$
M:=\left(\begin{array}{ccccc}
1 & \mu_{12} & \mu_{13} & \ldots & \mu_{1 n} \\
\mu_{21} & 1 & \mu_{23} & \ldots & \mu_{2 n} \\
\mu_{31} & \mu_{32} & 1 & \ldots & \mu_{3 n} \\
: & : & : & : & : \\
: & & & & : \\
\mu_{n 1} & \mu_{n 2} & \ldots & \mu_{n n-1} & 1
\end{array}\right) .
$$

The matrix $M$ describes how the agents' flat contributions $\left(y_{1}, \ldots, y_{n}\right)$ translate into their total contributions $\left(z_{1}, \ldots, z_{n}\right)$. To facilitate notation, the superscript " $\rightarrow$ " from now on is used to indicate vectors.

Proposition 7: A matching mechanism is a $\mathrm{W}$-scheme if and only if $\operatorname{det} M \neq 0$, i.e., the transformation matrix is non-singular.

Proof: "If": Consider some $\vec{w}=\left(w_{1}, \ldots, w_{n}\right) \in \Omega$. Proposition 5 then implies that there exists some $\overrightarrow{\tilde{y}}=\left(\tilde{y}_{1}, \ldots, \tilde{y}_{n}\right)$ with $\tilde{y}_{i}>0$ for all $i=1, \ldots, n$ such that $\vec{w}=M \overrightarrow{\tilde{y}}$. If, as supposed, the matrix $M$ is non-singular its inverse $A^{-1}$ exists, and $\overline{\tilde{y}}=M^{-1} \vec{w}$ holds. Since $M^{-1}$ is a supnorm-continuous function on $\square^{n}$ the vector $\overrightarrow{\tilde{y}}^{\prime}=M^{-1} \vec{w}^{\prime}$ also has strictly positive components for any income distribution $\tilde{w}^{\prime}=\left(w_{1}^{\prime}, \ldots, w_{n}^{\prime}\right)$ that is close to the original income distribution $\vec{w}=\left(w_{1}, \ldots, w_{n}\right)$. Since $\vec{w}^{\prime}=M \vec{y}^{\prime}$, the assertion then directly follows from Proposition 5.

"Only If": Assume that $\operatorname{det} M=0$ such that the matrix $M$ is singular. If the rank of $M$ then is $m<n, M$ maps $\square^{n}$ into a hyperplane $\mathrm{H}=M\left(\square^{n}\right)$ with dimension $m$. This hyperplane 
has a non-empty intersection with the simplex $\Gamma(W)$ because $\Omega$ is not empty from Proposition 6. Since, in addition, the origin $(0, \ldots, 0)$ obviously lies on $\mathrm{H}$ but not on $\Gamma(W)$ the intersection $\mathrm{H} \cap \Gamma(W)$ has dimension $m-1$ and thus a lower dimension than $\Gamma(W)$ (which is $n-1)$. Therefore, for any element $\overrightarrow{\tilde{w}}=\left(w_{1}, \ldots, w_{n}\right) \in \mathrm{H} \cap \Gamma(W)$ there is some other point in $\Gamma(W)$ close to $\overrightarrow{\tilde{w}}$, i.e., starting from $\overrightarrow{\tilde{w}}$ a small redistribution of income, which does not lie on $H$ and thus is not contained in $\Omega$. This shows that local Warr neutrality is violated in this case.

QED

The condition $\operatorname{det} M \neq 0$ which underlies Proposition 7 is tantamount to having a unique solution for the system of equations given by (11-i). Uniqueness of flat contributions in an interior matching equilibrium, however, has been in the focus of much of the existing literature on matching in a public goods economy (see Falkinger (1996) and Falkinger and Brunner 1999). By Proposition 7 it turns out that the uniqueness property is determined by just the same condition as local Warr neutrality. From this perspective, there is thus a double reason to be particularly interested in matching mechanisms for which the corresponding transformation matrix $M$ is non-singular. Note that this condition only refers to properties of the matching mechanism but not to specific characteristics of the economy as the preferences of the agents.

It is also an immediate consequence of Proposition 7 that small deviations from some originally given income distribution $\left(w_{1}, \ldots, w_{n}\right) \in \Omega$ will destroy Warr neutrality much more if the rank of the matrix $M$ is smaller since the dimension of $\mathrm{H}$ and thus $\mathrm{H} \cap \Gamma(W)$ then is reduced. In the extreme, when the matrix $M$ has rank 1, the set $\mathrm{H} \cap \Gamma(W)$ only contains one single element. Such a situation, e.g., prevails for matching schemes which implement Pareto optimal allocations in an economy with two agents where, as has been seen above in Section 4 , only tiny deviations from the "right" income distribution will lead away from the interior matching equilibrium. What the general criterion as described by Proposition 7 implies in specific situations will now be discussed in more detail. In particular, we will explore how specific Pareto optimal allocations can be attained by application of matching schemes that show the local Warr neutrality property.

\section{Specific Matching Schemes}

An outstanding Pareto-optimal solution in a public goods economy is that in which all agents have the same marginal rates of substitution between the private and the public good. If there 
are $n$ agents in the economy then, as a direct implication of the Samuelson rule, we have $m r s_{i}=n$ for any agent $i=1, \ldots, n$ in such a solution. This specific PIME in which all agents pay the same marginal price for the public good and in this sense are treated symmetrically (see Falkinger 1996) will be called $P_{s}$. The following Proposition shows that aiming at $P_{s}$ as matching equilibrium and at the same time imposing an additional equal treatment postulate will reduce the size of $\Omega$ to one such that local Warr neutrality is violated in a quite extreme way.

Proposition 8: If a matching scheme implements $P_{s}$ and no agent matches other agents by different matching rates, the set $\Omega$ only contains a single income distribution.

Proof: As in an interior matching equilibrium $m r s_{i}=1+\sigma_{i}$ holds for all agents it follows from $m r s=n$ (which specifically holds in $P_{s}$ ) and from $\mu_{j i}=\mu_{j}$ for all agents $j$ and $i$ with $j \neq i$ (which is the assumption on the matching mechanism made in the Proposition) that

$$
\sum_{\substack{j=1 \\ j \neq i}}^{n} \mu_{j}=n-1
$$

holds for each agent $i=1, \ldots, n$. By adding $\mu_{i}$ on both sides of eq. (23) we obtain

$$
\mu_{i}=\sum_{j=1}^{n} \mu_{j}-(n-1)=\mu=\text { const. } \quad \text { for all } i=1, \ldots, n
$$

Also from (23) we, moreover, get $(n-1) \mu=n-1$, which gives $\mu=1$. Hence, under the assumptions of Proposition 8, the transformation matrix $M$ is

$$
M=\left(\begin{array}{ccc}
1 & \ldots & 1 \\
: & & : \\
1 & \ldots & 1
\end{array}\right) .
$$

This matrix clearly has rank 1 since all its rows are identical. Therefore, there is exactly one income distribution $\left(\breve{w}_{1}, \ldots, \breve{w}_{n}\right)$ that yields the desired Pareto-optimal solution as an interior matching equilibrium.

QED

The only element of $\Omega$ that occurs in the situation described by Proposition 8 clearly must be identical with the income distribution that had been constructed in the proof of Proposition 6. According to eq. (18) all agents then make the same flat contribution $\tilde{y}$ whose level is 


$$
\tilde{y}=\frac{\hat{G}}{n+n \sigma}=\frac{\hat{G}}{n+n(n-1)}=\frac{\hat{G}}{n^{2}} .
$$

By eq. (18) the income distribution $\left(\breve{w}_{1}, \ldots, \breve{w}_{n}\right)$ which makes up $\Omega$ can be explicitly described by

$$
\breve{w}_{i}=\hat{x}_{i}+\frac{\hat{G}}{n} \quad \text { for all } i=1, \ldots, n .
$$

Obviously, this is the same income distribution that is required to have the PIME corresponding to $\sigma_{i}=\sigma=n-1$ as the Lindahl equilibrium when the personalized Lindahl prices $p_{i}^{L}$ are to be the same for all agents such that $p_{i}^{L}=\frac{1}{n}$ holds for all agents $i=1, \ldots, n$.

Proposition 8 provides the general insight that in order to implement a Pareto-optimal allocation as an interior matching equilibrium which is robust against small perturbations of the income distribution one has to give up either uniformity of the matching rates or uniformity of marginal rates of substitution in the equilibrium. There are several possibilities by which this can be achieved and which thus lead to Pareto optimal matching equilibria. Some of these options will now be analyzed.

It is an immediate consequence of Proposition 8 that, in the case with $n \geq 3$, there exist innumerable possibilities to construct matching schemes that implement $P_{s}$ and that, at the same time, have the local Warr neutrality (and uniqueness) property. It only has to be ensured that all rows of the matrix $M$ are linearly independent and the Samuelson rule (8) as given by Proposition 3 is fulfilled. An important subclass which will now be considered in more detail consists of matching mechanisms for which some matching rates $\mu_{i j}$ are zero, which means that at least some agents do not match the public good contributions of some other agents. A simple example of such a matching scheme, e.g., is given by the matching rates $\mu_{i i+1}=\mu_{n 1}=n-1$ for all $i=1, \ldots, n-1$ and $\mu_{i j}=0$ for all other matching rates, i.e., agent 1 only matches the public good contributions of agent 2, agent 2 only those of agent 3 etc., and to close the scheme, agent $n$ matches agent 1 . Thus we have a cyclical matching with $\sigma_{i}=n-1$ for each agent $i=1, \ldots, n$ such that the Pareto optimal solution $P_{s}$ is implemented. That for this specific matching scheme the transformation matrix $M$ is non-singular is shown in Lemma 1 in Appendix A1 when we specifically set $\mu=n-1$. Even though a matching scheme of this type does not seem to be of much empirical relevance it shows that a partioning of the whole 
economy in subgroups is actually not required to implement the Pareto optimal solution $P_{s}$ as a matching equilibrium.

A more important subclass of the matching schemes that have some zero matching rates is that which leads to matching on a reciprocal base: According to the do ut des principle an agent $i$ matches just those agents $j$ who pay matching grants to the public good contributions of agent $i$, i.e., $\mu_{i j}>0$ holds if and only if $\mu_{j i}>0$ for some agents $i, j=1, \ldots, n$, and $\mu_{i j}=0$ for at least one pair of agents $i, j=1, \ldots, n$ with $i \neq j$. In this case matching only happens among the members of the same group, and when identical matching rates are assumed for each group a groupwise homogeneous matching scheme (as devised by Falkinger 1996, and already described in Section 2) is obtained. Assume again that the total set of agents $I=\{1, \ldots, n\}$ is divided into $k$ subgroups $I_{1}, \ldots, I_{k}$ where the size of subgroup $I_{j}$ is denoted by $n_{j}$, and $\mu_{j}$ is the matching rate in group $I_{j}$. Then the following result holds.

Proposition 9: A groupwise homogeneous matching scheme is a $\mathrm{W}$-scheme if and only if $\mu_{j} \neq 1$ for each group $j=1, \ldots, k$.

Proof: Given such a matching scheme the transformation matrix $M$ can be written as

$$
M=\left(\begin{array}{cccc}
M_{1} & 0 & . . & 0 \\
0 & M_{2} & . . & 0 \\
: & . & . & : \\
0 & \ldots & 0 & M_{k}
\end{array}\right)
$$

where each $n_{j} \times n_{j}$-submatrix $M_{j}$, which is the transformation matrix for group $I_{j}$, is of the form

$$
M_{j}=\left(\begin{array}{cccc}
1 & \mu_{j} & \ldots & \mu_{j} \\
\mu_{j} & 1 & \cdots & \mu_{j} \\
: & : & : & : \\
\mu_{j} & \cdots & \mu_{j} & 1
\end{array}\right) .
$$

It follows from Lemma 2 in Appendix A2 that $\operatorname{det} M_{j} \neq 0$ if and only if $\mu_{j} \neq 1$. The assertion in Proposition 9 then follows from $\operatorname{det} M=\prod_{j=1}^{k} \operatorname{det} M_{j}$, which is a general fact if the matrix $M$ is of the type as in (27).

QED

If the Samuelson rule holds for a groupwise homogeneous matching scheme, i.e., 


$$
\sum_{j=1}^{k} \frac{n_{j}}{1+\left(n_{j}-1\right) \mu_{j}}=1
$$

with $\mu_{j} \neq 1$ for all $j=1, \ldots, k$, then a Pareto-optimal solution is implemented. Condition (29) is not empty, which is an implication of the following Proposition.

Proposition 10: If the number of agents $n$ exceeds 3, the Pareto-optimal allocation $P_{s}$ in which all agents have the same marginal rate of substitution can be implemented by a groupwise homogeneous matching scheme.

Proof: Setting $\mu_{j}=\frac{n-1}{n_{j}-1} \quad$ for $j=1, \ldots, k$ implies $\sigma_{i}=1+\left(n_{j}-1\right) \frac{n-1}{n_{j}-1}=n$ if agent $i$ is in group $I_{i}$. This shows that $P_{s}$ is implemented. The local Warr neutrality property then follows from Proposition 9.

QED

As local Warr neutrality is equivalent to uniqueness of the matching scheme in flat contributions, Proposition 10 confirms the important result by Falkinger (1996) in an alternative way. Note that the groupwise homogeneous matching scheme that implements $P_{s}$ is, according to Proposition 10, not uniquely determined. Rather, the division of the whole group of agents into disjoint subgroups can be carried out in different ways. It only matters that there is some partitioning at all. So it is, e.g., possible to get local Warr neutrality by having subgroups of equal size $n_{j}=2$ if the total number $n \geq 4$ of agents is even such that matching is pairwise. If $n \geq 5$, however, is odd one may choose all subgroups of size 2 except one whose size is 3. Only if the total number of agents $n$ is equal to 3, Proposition 10 cannot be applied and $P_{s}$ has to be implemented by another type of matching mechanism like, e.g., the cyclical mechanism that was described above.

If a matching scheme is based on a partitioning of the whole economy into different subgroups it is well possible to implement $P_{s}$ by an asymmetric scheme in which there is also matching between the groups. Such a matching scheme can, e.g., be constructed in the following way. Let there be two subgroups $I_{1}$ and $I_{2}$ in which there are $n_{1} \geq 2$ and $n_{2} \geq 1$ agents, respectively. Then all members of group $I_{1}$ match themselves in a symmetric way with the matching rate $\mu_{1}$ and also match the public good contributions of the agents in group $I_{2}$ by a possibly different matching rate $\mu_{2}$. The agents in group $I_{2}$, however, do not match any other public good contribution, neither in their same group $I_{2}$ or in the other group $I_{1}$. 
With regard to one-sided matching between two groups in the context of climate change or other global public goods, the matching group $I_{1}$ can be interpreted as the group of rich industrialized countries whereas the group $I_{2}$, whose members receive matching grants, are the poor developing countries.

The matching schemes of this type can formally be characterized by the following conditions:

$$
\begin{aligned}
& \mu_{i j}=\mu_{1} \text { if } i, j \in I_{1} \text { with } i \neq j \\
& \mu_{i j}=\mu_{2} \text { if } i \in I_{1} \text { and } j \in I_{2} \\
& \mu_{i j}=0 \text { if } i \in I_{2} \text { and all } j \in I
\end{aligned}
$$

For such matching schemes we have the following result on local Warr neutrality.

Proposition 11: A matching scheme as described by (30-1), (30-2) and (30-3) is a W-scheme if and only if $\mu_{1} \neq 1$.

Proof: Given (30-1), (30-2) and (30-3) the $n \times n$ transformation matrix is

$$
M=\left(\begin{array}{ll}
M_{11} & M_{12} \\
M_{21} & M_{22}
\end{array}\right)
$$

where $M_{11}$ is the $n_{1} \times n_{1}$-matrix $M_{11}=\left(\begin{array}{cccc}1 & \mu_{1} & \ldots & \mu_{1} \\ \mu_{1} & 1 & \ldots & \mu_{1} \\ : & : & : & : \\ \mu_{1} & 1 & \ldots & 1\end{array}\right), M_{12}$ is the $n_{1} \times n_{2}$-matrix $M_{12}=\left(\begin{array}{ccc}\mu_{2} & \ldots & \mu_{2} \\ : & & : \\ \mu_{2} & \ldots & \mu_{2}\end{array}\right), M_{21}$ is the $n_{2} \times n_{1}$-matrix $M_{21}=\left(\begin{array}{ccc}0 & \ldots & 0 \\ : & & : \\ 0 & \ldots & 0\end{array}\right)$ and $M_{22}$ is the $n_{2} \times n_{2}-$ matrix

$$
M_{22}=\left(\begin{array}{cccc}
1 & 0 & \ldots & 0 \\
0 & 1 & \ldots & 0 \\
: & : & : & : \\
0 & \ldots & 0 & 1
\end{array}\right)
$$


From standard rules in matrix calculus we $g e t \operatorname{det} M=\operatorname{det} M_{11} \cdot \operatorname{det} M_{22}=\operatorname{det} M_{11}$ since $\operatorname{det} M_{11}=1$. As the Lemma in Appendix A2 shows that $\operatorname{det} M_{11} \neq 0$ holds if and only if $\mu_{1} \neq 1$, the assertion of Proposition 11 directly follows from Proposition 7.

QED

Proposition 11 can now be applied to provide an alternative option for the implementation of $P_{s}$.

Proposition 12: The allocation $P_{s}$ can be implemented by a matching scheme that fulfils conditions (30-1), (30-2) and (30-3). Any such matching mechanism is a W-scheme.

Proof: We specifically set $\mu_{1}=\frac{n-1}{n_{1}-1} \quad$ and $\quad \mu_{2}=\frac{n-1}{n_{1}}$ which gives $m r s_{i}=1+\left(n_{1}-1\right) \mu_{1}=1+\left(n_{1}-1\right) \frac{n-1}{n_{1}-1}=n \quad$ for $\quad$ all agents $\quad i \quad$ in group $\quad I_{1}$ and $m r s_{i}=1+n_{1} \mu_{2}=1+n_{1} \frac{n-1}{n_{1}}=n$ for all agents $i$ in group $I_{2}$. This shows that $P_{s}$ can be implemented by such a scheme as an interior matching equilibrium. Local Warr neutrality then follows from Proposition 11, since $n_{1}<n$ gives $\mu_{1}=\frac{n-1}{n_{1}-1} \neq 1$.

QED

It is obvious from our general considerations in Section 5 that the one-sided mechanisms given by conditions (30-1), (30-2) and (30-3) also imply uniqueness in flat contributions as the other desirable property of interior matching equilibria.

\section{Increasing the Size of the Economy}

Since Olson (1965) it has been a central issue in the theory of public goods how the size of the economy affects the possibility of attaining an efficient solution (see Sandler 1992, pp. 52-54, for a formal treatment in the standard case of voluntary public good provision). In order to analyze this question in the matching context we assume that the originally given economy with $n \geq 2$ agents (that, as above, is characterized by utility functions $u_{i}\left(x_{i}, G\right)$ and income levels $w_{i}$ for $\left.i=1, \ldots, n\right)$ is replicated $m$ times. In any replication economy we consider the specific Pareto optimal PIME $P_{s}(m)$ in which $\sigma_{j}=m \cdot n-1$ holds for any agent $j=1, \ldots, m \cdot n$ such that the marginal rate of substitution between the private and the public good is $m r s=m \cdot n$ for all agents. By $\hat{G}(m)$ we denote public good supply in $P_{s}(m)$ and by $\hat{x}_{i}(m)$ 
private consumption of an agent $i=1, \ldots, n$. To get some result on the possibility to implement of $P_{s}(m)$ we have to assume that private consumption has a lower bound when the number of replications goes to infinity. This assumption, however, is rather weak and, e.g., fulfilled when preferences are of Cobb-Douglas type.

Assumption LB: If the replication factor $m$ increases, then each agent $i$ 's $(i=1, \ldots, n)$ private consumption in $P_{s}(m)$ is strictly bounded away from zero, i.e., $\underline{x}:=\min _{\substack{i=1, \ldots, n \\ m \in \square}}\left\{\hat{x}_{1}(m), \ldots, \hat{x}_{n}(m)\right\}>0$.

Given this assumption we obtain the following result.

Proposition 12: Given assumption LB, for any $\varepsilon>0$ there is a replication factor $m(\varepsilon)$ such that for any income distribution $\left(w_{1}, \ldots, w_{n}\right)$ with $w_{i}>(1+\varepsilon) \hat{x}_{i}(m)$ for all $i=1, \ldots, n$ the Pareto optimal allocation $P_{s}(m)$ can be implemented as an interior matching equilibrium by a Wscheme.

Proof: We distinguish two cases depending on whether the size $n$ of the original economy is even or odd and then construct a matching mechanism which has the local Warr neutrality property in the following way.

(i) If $n$ is even we arbitrarily split up the original economy in $k=\frac{n}{2}$ subgroups of size 2 in which there is pairwise matching. To attain $P_{s}(m)$ the matching rate of each agent then has to be $\mu(m)=m \cdot n-1>1$ for any agent $i$ if agent $j$ is in the same group but zero if agent $j$ is in another subgroup. For any subgroup $l=1, \ldots, k$ let $w_{i}^{(l)}$ denote the income of each of its two members $i=1,2, \hat{x}_{i}^{(l)}(m)$ their levels of private consumption in $P_{s}(m)$ and $\hat{z}_{i}^{(l)}(m)=$ $w_{i}^{(l)}-\hat{x}_{i}^{(l)}(m)$ their spending for the public good if the replication factor is $m$. To find out whether this matching mechanism in fact implements $P_{s}(m)$ for the given income distribution we apply Proposition 6. This means that we must check whether the system of the two equations

$$
\begin{aligned}
& y_{1}^{(l)}+\mu(m) y_{2}^{(l)}=\hat{z}_{1}^{(l)}(m) \\
& y_{2}^{(l)}+\mu(m) y_{1}^{(l)}=\hat{z}_{2}^{(l)}(m)
\end{aligned}
$$


has strictly positive solutions in $y_{1}^{(l)}$ and $y_{2}^{(l)}$. Quite analogous to condition (16-2) which applies when the whole economy only consists of two agents this is the case if and only if

$$
\begin{aligned}
& \frac{\hat{z}_{1}^{(l)}(m)}{\hat{z}_{2}^{(l)}(m)}<\mu(m) \quad \text { and } \\
& \frac{\hat{z}_{2}^{(l)}(m)}{\hat{z}_{1}^{(l)}(m)}<\mu(m) .
\end{aligned}
$$

Now for any given $\varepsilon>0$ we choose

$$
m(\varepsilon) \geq \frac{1}{n}\left(\frac{W}{\varepsilon \underline{x}}+1\right)
$$

where again $W=\sum_{i=1}^{n} w_{i}$ is the total income in the original $n$-person economy and $\underline{x}$ is the lower bound for individual private consumption according to assumption LB. Then we can make the following estimate when, as in the Proposition, $w_{2}>(1+\varepsilon) \hat{x}_{2}(m)$ is assumed:

$$
\frac{\hat{z}_{1}^{(l)}(m)}{\hat{z}_{2}^{(l)}(m)}<\frac{W}{w_{2}^{(l)}-\hat{x}_{2}^{(l)}(m)}<\frac{W}{(1+\varepsilon) \hat{x}_{2}^{(l)}(m)-\hat{x}_{2}^{(l)}(m)}=\frac{W}{\varepsilon \hat{x}_{2}^{(l)}(m)}<\frac{W}{\varepsilon \underline{x}}<m \cdot n-1=\mu(m) .
$$

In (35) the last inequality is implied by the choice of $m(\varepsilon)$ as described by (34). This gives condition (33-1). The other condition (33-2) follows in a quite analogous way from the assumption $w_{1}>(1+\varepsilon) \hat{x}_{1}(m)$ which proves Proposition 12 when $n$ is even.

(ii) If $n \geq 5$ is odd we split up the original economy in $k-1=\frac{n-1}{2}$ subgroups $i=1, \ldots, k-1$ of size 2 in which there is pairwise matching as in part (i) of the proof and the subgroup $k$ with three members. (In the case $n=3$ there is only this group with three members.) For any replication factor $m$ the matching mechanism for this group $k$ is given by the following $3 \times 3$-transformation matrix:

$$
M^{(k)}(m)=\left(\begin{array}{ccc}
1 & \mu(m) & 1 \\
0 & 1 & \mu(m) \\
\mu(m) & 0 & 1
\end{array}\right)
$$

To show that $P_{s}(m)$ is implemented by the matching mechanism thus described, for the subgroups $l=1, \ldots, k-1$ of size 2 the same conditions as in part (i) must hold such that the 
argument is completely identical. For subgroup $k$, however, the implementability condition on the income levels $\left(w_{1}^{(k)}, w_{2}^{(l)}, w_{3}^{(l)}\right)$ and the concomitant values $\left(\hat{z}_{1}^{(k)}, \hat{z}_{2}^{(l)}, \hat{z}_{3}^{(l)}\right)$ now is that the system of the three equations

$$
\begin{aligned}
& y_{1}^{(k)}+\mu(m) y_{2}^{(k)}=\hat{z}_{1}^{(k)} \\
& y_{2}^{(k)}+\mu(m) y_{3}^{(k)}=\hat{z}_{2}^{(k)} \\
& y_{3}^{(k)}+\mu(m) y_{1}^{(k)}=\hat{z}_{3}^{(k)}
\end{aligned}
$$

must have strictly positive solutions in the flat contributions $y_{1}^{(k)}, y_{2}^{(k)}$ and $y_{3}^{(k)}$. A short calculation shows that the solutions of (36-1), (36-2) and (36-3) are given by

$$
\tilde{y}_{i_{1}}^{(k)}(m)=\frac{\hat{z}_{i_{1}}(m)+\mu(m)\left(\mu(m) \hat{z}_{i_{3}}(m)-\hat{z}_{i_{2}}(m)\right)}{1+\mu(m)^{3}}
$$

if $\left(i_{1}, i_{2}, i_{3}\right)$ is either $(1,2,3),(2,3,1)$ or $(3,1,2)$. For $\tilde{y}_{i_{1}}^{(k)}(m)>0$ (where $\left.i_{1}=1,2,3\right)$ it is thus sufficient that

$$
\frac{\hat{z}_{i_{2}}^{(k)}}{\hat{z}_{i_{3}}^{(k)}}<\mu(m)
$$

if either $\left(i_{2}, i_{3}\right)$ is $(2,3),(3,1)$ or $(1,2)$. Now for any $\varepsilon>0$ the replication factor $m(\varepsilon)$ is again chosen according to eq. (34). Then condition (38) is fulfilled which follows in quite the same way as in case (i).

The transformation matrix of the matching mechanism constructed in (i) and (ii) is nonsingular. This follows in the same way as in the proof of Proposition 9 since the transformation matrices for the subgroups of two and the subgroup of three agents are nonsingular. Local Warr neutrality and thus uniqueness then is implied by Proposition 7. QED

Similar as in Definition 3, the set of income distributions $\left(w_{1}, \ldots, w_{n}\right)$ for which $w_{i}>\hat{x}_{i}(m)$ holds for all $i=1, \ldots, n$ is denoted by $\Pi_{s}(m)$. Analogously, let $\Omega_{s}(m)$ be the set of income distributions $\left(w_{1}, \ldots, w_{n}\right)$ for which $P_{s}(m)$ is implemented by the matching mechanism constructed in the proof of Proposition 12. Then the result given by Proposition 12 may also be interpreted by saying that the set of income distributions $\Omega_{s}(m)$ converges to $\Pi_{s}(m)$ when the replication factor $m$ goes to infinity. This means that in large economies the 
additional restrictions on income distributions to make $P_{s}(m)$ implementable are less restrictive than in a small economy. Remember that we have seen in our analysis of the case $n=2$ in Section 4 that implementation of $P_{s}(2)$ is only feasible for a single income distribution. That implementation becomes easier when the size of the economy grows contradicts in some sense a hypothesis formulated by Brunner and Falkinger (1999, p. 359) which states that having no free riders under a given matching mechanism is "plausible if the number of the individuals in the economy is small".

For the subgroups with two agents that played the central role in the proof of Proposition 12, the result of this Proposition can easily be visualized by Figure 3.

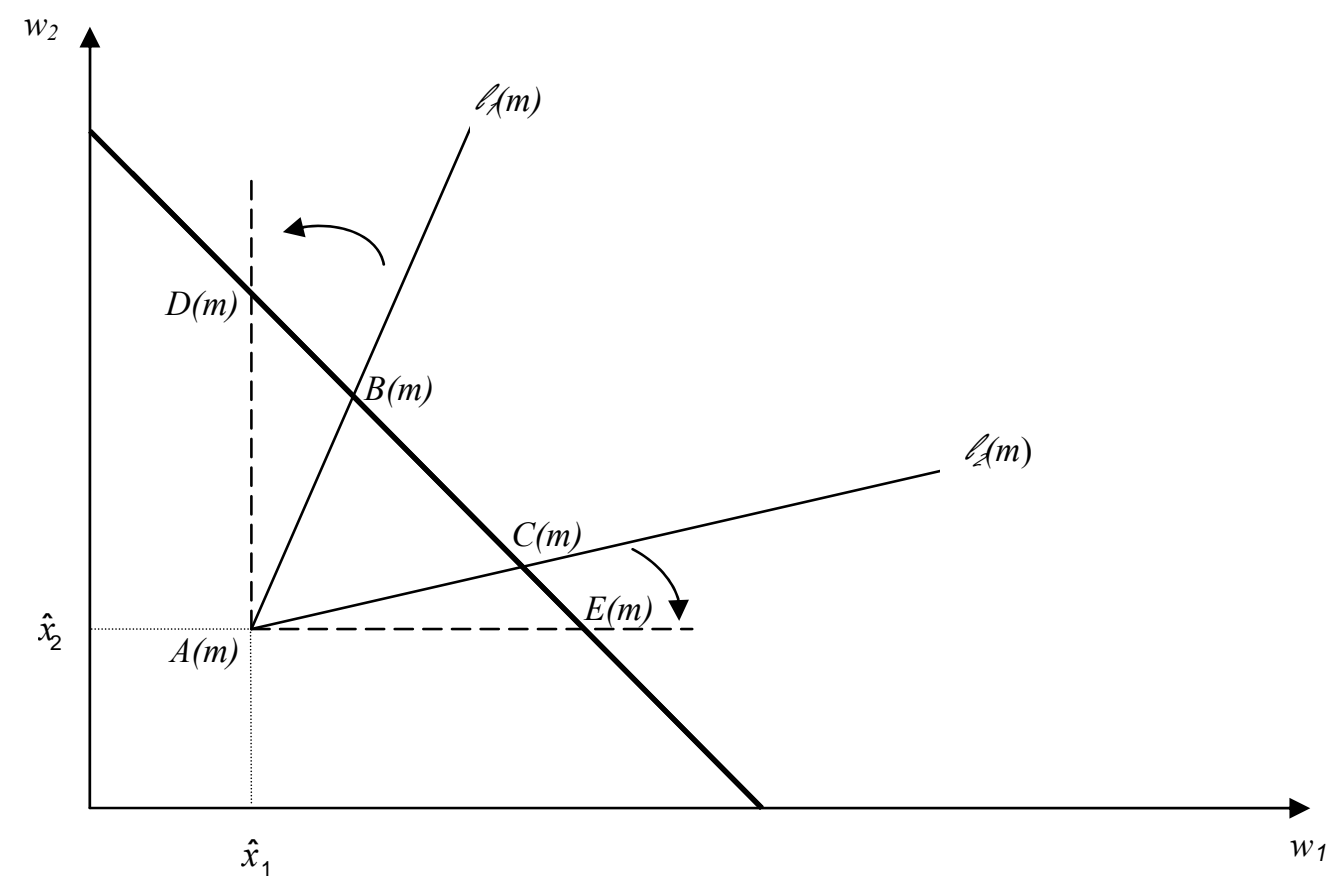

Figure 3: Change of $\ell_{1}(m)$ and $\ell_{2}(m)$ with $\mu(m)$ going to infinity.

In this figure, similar as in Figure 2 of Section 4, conditions (33-1) and (33-2) imply that all income distributions in $\Omega_{s}(m)$ must lie below the straight line $\ell_{1}(m)$ with slope $\mu(m)$ and above the straight line $\ell_{2}(m)$ with slope $\frac{1}{\mu(m)}$. Since $\mu(m)$ goes to infinity if $m$ is increased the segment $B(m) C(m)$ which describes $\Omega_{s}(m)$ approximates the segment $D(m) E(m)$ which represents the set $\Pi_{s}(m)$ in Figure 3. 


\section{Conclusion}

Reciprocal matching in a public good economy has become an important topic in public good theory that, in the context with the pertinent political task to overcome underprovision of global public goods, also is of empirical importance. As an instrument for improving public good provision in a world without a well-established central government matching promises to combine different attractive features. On the one hand, it helps to avoid problems of asymmetric information about individual costs and benefits of the public good that exist between the participating agents and the central agency. The reason is that Pareto optimal allocation may be attained by rather schematic types of matching mechanisms for which specific knowledge about the agents is not important. On the other hand, there is no need for a central agency that - as in the case of a domestic government - directly has to enforce the public good contributions of the agents. Instead the agents still make their independent choices, and it only has to be ensured that while doing this, they really observe the rules of the matching mechanism.

Apart from these advantages of matching the literature, however, has also identified some obstacles that may impede the application of a matching mechanism. So above all it has been shown that for some simple and otherwise appealing mechanisms the matching equilibria are not unique which at least demands some additional coordination efforts of the agents. Against this background the main message of our paper is that beyond uniqueness there are other severe problems with the functioning of matching schemes. So existence of interior matching equilibria in which all agents voluntarily make a positive contribution to the public good is not guaranteed but - depending on the precise form of the mechanism - requires quite specific distributions of initial income. Therefore, in order to make a matching scheme workable, some redistribution of income among the agents may be warranted at first. To find an appropriate income distribution, however, will not be possible without detailed knowledge about the agents' characteristics which reduces the informational advantages of matching. Moreover, as we have also shown in our analysis, there is a non-negligible danger that only slightly missing the appropriate income distributions will inevitably lead the matching equilibrium away from the desired solution. The problem of local Warr non-neutrality can be avoided if only matching mechanisms are used that fulfil a certain regularity condition which, interestingly, coincides with that for uniqueness. Therefore there is a double advantage of applying regular matching mechanisms.

The class of matching mechanisms that provide Warr neutrality and uniqueness is much larger than that on which the previous literature has focused, i.e., the class of matching 
schemes where reciprocal matching only occurs within distinct groups. An alternative is, e.g., to restrict active payments into the matching scheme to some group of donors whereas the other members of the economy outside this group only receive matching grants out of the scheme. We have also seen that in very small economies it is quite unlikely that a Pareto optimal allocation is attained through matching. But if the size of the economy is increased, e.g., by replication of the original economy, then - by application of a specifically constructed matching mechanism - the set of income distributions which allows for implementation of Pareto optimal allocations will be growing, too. Thus it is a main and not quite unsurprising insight of our paper that matching may work better in large than in small economies.

Acknowledgements: The work of Wolfgang Buchholz was supported by the Deutsche Forschungsgemeinschaft DFG as part of the "Schwerpunktprogramm: Institutionelle Gestaltung föderaler Systeme: Theorie und Empirie". The work Dirk T.G. Rübbelke devoted to this paper is funded under the project "Integration of Air Quality and Climate Policies" sponsored by the Research Council of Norway.

\section{Appendix A1}

Lemma 1: If $M=\left(\begin{array}{cccccc}1 & \mu & 0 & 0 & \ldots & 0 \\ 0 & 1 & \mu & 0 & \ldots & 0 \\ 0 & 0 & 1 & \mu & \ldots & 0 \\ : & & & . & & : \\ : & & & & . & : \\ \mu & 0 & . & . & . & 1\end{array}\right)$ and $\mu \neq 1$, then $\operatorname{det} M \neq 0$.

Proof: We have by standard rules for calculation of determinants

$\operatorname{det} M=1 \cdot \operatorname{det}\left(\begin{array}{cccccc}1 & \mu & 0 & 0 & \ldots & 0 \\ 0 & 1 & \mu & 0 & \ldots & 0 \\ 0 & 0 & 1 & \mu & \ldots & 0 \\ : & & & & & : \\ : & & & & & : \\ 0 & 0 & . . & . . & 0 & 1\end{array}\right)$
$=1-\mu(-1)^{n-2} \operatorname{det}\left(\begin{array}{cccccc}\mu & 0 & . . & . . & 0 & 0 \\ 1 & \mu & 0 & . . & . . & 0 \\ 0 & 1 & \mu & 0 & \ldots & 0 \\ : & & & & & : \\ : & & & & & \\ 0 & . . & . . & 0 & 1 & \mu\end{array}\right)=1+(-1)^{n-1} \mu^{n}$. Thus, if $n$ is an odd number

$\operatorname{det} M>0$ holds for any $\mu$, if $n$ is an even number $\operatorname{det} M \neq 0$ holds if $\mu \neq 1$. 


\section{Appendix A2}

Lemma 2: If $M=\left(\begin{array}{ccccc}1 & \mu & \mu & \ldots & \mu \\ \mu & 1 & \mu & \ldots & \mu \\ : & & . & & : \\ : & & & . & : \\ \mu & \mu & \ldots & \mu & 1\end{array}\right)$ and $\mu>0$, then $\operatorname{det} M \neq 0$ if and only if $\mu \neq 1$.

Proof: By elementary transformations of the matrix $M$ we get

$$
\begin{gathered}
\operatorname{det} M=\operatorname{det}\left(\begin{array}{ccccc}
1 & \mu & \ldots & \mu & \mu \\
\mu-1 & 1-\mu & 0 & \ldots & 0 \\
\mu-1 & 0 & 1-\mu & \ldots & 0 \\
: & & & & : \\
: & & & & : \\
\mu-1 & 0 & \ldots & 0 & 1-\mu
\end{array}\right)=\operatorname{det}\left(\begin{array}{ccccc}
1+(n-1) \mu & \mu & \ldots & \mu & \mu \\
0 & 1-\mu & 0 & \ldots & 0 \\
0 & 0 & 1-\mu & \ldots & 0 \\
: & & & & : \\
: & & & & : \\
0 & 0 & \ldots & 0 & 1-\mu
\end{array}\right) \\
=(1+(n-1) \mu) \cdot(1-\mu)^{n-1} .
\end{gathered}
$$

If $\mu>0$, then this expression clearly is non-zero if and only if $\mu \neq 1$. 


\section{References}

Althammer, W. and Buchholz, W. (1993), Lindahl-Equilibria as the Outcome of a Noncooperative Game, European Journal of Political Economy 9: 399-405.

Andreoni, J. and Bergstrom, T.C. (1996), Do Government Subsidies Increase the Private Supply of Public Goods?, Public Choice 88: 295-308.

Bergstrom, T.C.; Blume, L. and Varian, H. (1986), On the Private Provision of Public Goods, Journal of Public Economics 29: 25-49.

Barrett, S. (1990), The Problem of Global Environmental Protection, Oxford Review of Economic Policy 6: 68-79.

Boadway, R.; Pestieau, P. and Wildasin, D. (1989), Tax-transfer Policies and the Voluntary Provision of Public Goods, Journal of Public Economics 39: 157-176.

Boadway, R.; Song, Z. and Tremblay, J.-F. (2007), Commitment and Matching Contributions to Public Goods, Journal of Public Economics 91: 1664-1683.

Buchholz, W.; Cornes, R.C. and Peters, W. (2006), On the Frequency of Interior CournotNash Equilibria in a Public Good Economy, Journal of Public Economic Theory 8: 401-408.

Cornes, R.C. (2009), The Voluntary Contribution Model of Public Goods, The New Palgrave Dictionary of Economics, Online Edition.

Cornes, R.C. and Hartley, R. (2003), Risk Aversion, Heterogeneity and Contests, Public Choice 117: 1-25.

Cornes, R.C. and Hartley, R. (2007), Aggregative Public Good Games, Journal of Public Economic Theory 9: 201-219.

Cornes, R.C. and Sandler, T. (1985), The Simple Analytics of Pure Public Good Provision, Economica 52: 103-116.

Cornes, R.C. and Sandler, T. (1989), Public Goods, Growth, and Welfare, Social Choice and Welfare 6: 243-251.

Cornes, R.C. and Sandler, T. (1996), The Theory of Externalities, Public Goods and Club Goods, Cambridge University Press (Cambridge).

Danziger, L. and Schnytzer, A. (1991), Implementing the Lindahl Voluntary-exchange Mechanism, European Journal of Political Economy 7: 55-64.

Falkinger, J. (1996), Efficient Private Provision of Public Goods by Rewarding Deviations from Average, Journal of Public Economics 62: 413-422.

Falkinger, J. and Brunner, J.K. (1999), Taxation in an Economy with Private Provision of Public Goods, Review of Economic Design 4: 357-379.

Falkinger, J.; Hackl, F. and Pruckner, G.J. (1996), A Fair Mechanism for Efficient Reduction of Global $\mathrm{CO}_{2}$-emissions, FinanzArchiv/Public Finance Analysis 53: 308-331.

Guttman, J.M. (1978), Understanding Collective Action: Matching Behavior, American Economic Review 68: 251-255.

Guttman, J.M. (1987), A Non-Cournot Model of Voluntary Collective Action, Economica 54: $1-19$.

Ihori, T. (1996), International Public Goods and Contribution Productivity Differentials, Journal of Public Economics 61: 139-154. 
Kirchsteiger, G. and Puppe, C. (1997), On the Possibility of Efficient Private Provision of Public Goods through Government Subsidies, Journal of Public Economics 66: 489504.

Kotchen, M.J. (2009), Voluntary Provision of Public Goods for Bads: A Theory of Environmental Offsets, Economic Journal 119: 883-899.

Lindahl, E. (1919), Die Gerechtigkeit der Besteuerung, Glerupska Universitets Bokhandeln (Lund).

Nordhaus, W.D. (2006), After Kyoto: Alternative Mechanisms to Control Global Warming, American Economic Review 96: 31-34.

Olson, M. (1965), The Logic of Collective Action, Harvard University Press (Cambridge, MA).

Pigou, A.C. (1920), The Economics of Welfare, Macmillan (London).

Roberts, R.D. (1987), Financing Public Goods, Journal of Political Economy 95: 420-437.

Roberts, R.D. (1992), Government Subsidies to Private Spending on Public Goods, Public Choice 74: 133-152.

Sandler, T. (1992), Collective Action: Theory and Applications, Harvester Wheatsheaf (New York et al.)

Shrestha, R.K. and Cheong, K.S. (2007), An Alternative Algorithm for Identifying Free Riders Based on a No-Free-Rider Nash Equilibrium, FinanzArchiv/Public Finance Analysis 63: 278-284.

Varian, H. (1994a), Sequential Contributions to Public Goods, Journal of Public Economics 53: $165-186$.

Varian, H. (1994b), A Solution to the Problem of Externalities when Agents are Wellinformed, American Economic Review 84: 1278-1293.

Warr, P.G. (1982), Pareto Optimal Redistribution and Private Charity, Journal of Public Economics 19: 131-138.

Warr, P.G. (1983), The Private Provision of a Public Good is Independent of the Distribution of Income, Economics Letters 13: 207-211. 


\section{CESifo Working Paper Series}

for full list see www.cesifo-group.org/wp

(address: Poschingerstr. 5, 81679 Munich, Germany, office@cesifo.de)

2821 Panu Poutvaara and Andreas Wagener, The Political Economy of Conscription, October 2009

2822 Steinar Holden and Åsa Rosén, Discrimination and Employment Protection, October 2009

2823 David G. Mayes, Banking Crisis Resolution Policy - Lessons from Recent Experience Which elements are needed for robust and efficient crisis resolution?, October 2009

2824 Christoph A. Schaltegger, Frank Somogyi and Jan-Egbert Sturm, Tax Competition and Income Sorting: Evidence from the Zurich Metropolitan Area, October 2009

2825 Natasa Bilkic, Thomas Gries and Margarethe Pilichowski, Stay in School or Start Working? - The Human Capital Investment Decision under Uncertainty and Irreversibility, October 2009

2826 Hartmut Egger and Udo Kreickemeier, Worker-Specific Effects of Globalisation, October 2009

2827 Alexander Fink and Thomas Stratmann, Institutionalized Bailouts and Fiscal Policy: The Consequences of Soft Budget Constraints, October 2009

2828 Wolfgang Ochel and Anja Rohwer, Reduction of Employment Protection in Europe: A Comparative Fuzzy-Set Analysis, October 2009

2829 Rainald Borck and Martin Wimbersky, Political Economics of Higher Education Finance, October 2009

2830 Torfinn Harding and Frederick van der Ploeg, Is Norway's Bird-in-Hand Stabilization Fund Prudent Enough? Fiscal Reactions to Hydrocarbon Windfalls and Graying Populations, October 2009

2831 Klaus Wälde, Production Technologies in Stochastic Continuous Time Models, October 2009

2832 Biswa Bhattacharyay, Dennis Dlugosch, Benedikt Kolb, Kajal Lahiri, Irshat Mukhametov and Gernot Nerb, Early Warning System for Economic and Financial Risks in Kazakhstan, October 2009

2833 Jean-Claude Trichet, The ECB's Enhanced Credit Support, October 2009

2834 Hans Gersbach, Campaigns, Political Mobility, and Communication, October 2009

2835 Ansgar Belke, Gunther Schnabl and Holger Zemanek, Real Convergence, Capital Flows, and Competitiveness in Central and Eastern Europe, October 2009 
2836 Bruno S. Frey, Simon Luechinger and Alois Stutzer, The Life Satisfaction Approach to Environmental Valuation, October 2009

2837 Christoph Böhringer and Knut Einar Rosendahl, Green Serves the Dirtiest: On the Interaction between Black and Green Quotas, October 2009

2838 Katarina Keller, Panu Poutvaara and Andreas Wagener, Does Military Draft Discourage Enrollment in Higher Education? Evidence from OECD Countries, October 2009

2839 Giovanni Cespa and Xavier Vives, Dynamic Trading and Asset Prices: Keynes vs. Hayek, October 2009

2840 Jan Boone and Jan C. van Ours, Why is there a Spike in the Job Finding Rate at Benefit Exhaustion?, October 2009

2841 Andreas Knabe, Steffen Rätzel and Stephan L. Thomsen, Right-Wing Extremism and the Well-Being of Immigrants, October 2009

2842 Andrea Weber and Christine Zulehner, Competition and Gender Prejudice: Are Discriminatory Employers Doomed to Fail?, November 2009

2843 Hadi Salehi Esfahani, Kamiar Mohaddes and M. Hashem Pesaran, Oil Exports and the Iranian Economy, November 2009

2844 Ruediger Bachmann and Christian Bayer, Firm-Specific Productivity Risk over the Business Cycle: Facts and Aggregate Implications, November 2009

2845 Guglielmo Maria Caporale, Burcu Erdogan and Vladimir Kuzin, Testing for Convergence in Stock Markets: A Non-Linear Factor Approach, November 2009

2846 Michèle Belot and Jan Fidrmuc, Anthropometry of Love - Height and Gender Asymmetries in Interethnic Marriages, November 2009

2847 Volker Nitsch and Nikolaus Wolf, Tear Down this Wall: On the Persistence of Borders in Trade, November 2009

2848 Jan K. Brueckner and Stef Proost, Carve-Outs Under Airline Antitrust Immunity, November 2009

2849 Margarita Katsimi and Vassilis Sarantides, The Impact of Fiscal Policy on Profits, November 2009

2850 Scott Alan Carson, The Relationship between Stature and Insolation: Evidence from Soldiers and Prisoners, November 2009

2851 Horst Raff and Joachim Wagner, Intra-Industry Adjustment to Import Competition: Theory and Application to the German Clothing Industry, November 2009

2852 Erkki Koskela, Impacts of Labor Taxation with Perfectly and Imperfectly Competitive Labor Markets under Flexible Outsourcing, November 2009 
2853 Cletus C. Coughlin and Dennis Novy, Is the International Border Effect Larger than the Domestic Border Effect? Evidence from U.S. Trade, November 2009

2854 Johannes Becker and Clemens Fuest, Source versus Residence Based Taxation with International Mergers and Acquisitions, November 2009

2855 Andreas Hoffmann and Gunther Schnabl, A Vicious Cycle of Manias, Crashes and Asymmetric Policy Responses - An Overinvestment View, November 2009

2856 Xavier Vives, Strategic Supply Function Competition with Private Information, November 2009

2857 M. Hashem Pesaran and Paolo Zaffaroni, Optimality and Diversifiability of Mean Variance and Arbitrage Pricing Portfolios, November 2009

2858 Davide Sala, Philipp J.H. Schröder and Erdal Yalcin, Market Access through Bound Tariffs, November 2009

2859 Ben J. Heijdra and Pim Heijnen, Environmental Policy and the Macroeconomy under Shallow-Lake Dynamics, November 2009

2860 Enrico Spolaore, National Borders, Conflict and Peace, November 2009

2861 Nina Czernich, Oliver Falck, Tobias Kretschmer and Ludger Woessmann, Broadband Infrastructure and Economic Growth, December 2009

2862 Evžen Kočenda and Martin Vojtek, Default Predictors and Credit Scoring Models for Retail Banking, December 2009

2863 Christian Gollier and Martin L. Weitzman, How Should the Distant Future be Discounted when Discount Rates are Uncertain?, December 2009

2864 Tiberiu Dragu and Mattias Polborn, Terrorism Prevention and Electoral Accountability, December 2009

2865 Torfinn Harding and Beata Smarzynska Javorcik, A Touch of Sophistication: FDI and Unit Values of Exports, December 2009

2866 Matthias Dischinger and Nadine Riedel, There's no Place like Home: The Profitability Gap between Headquarters and their Foreign Subsidiaries, December 2009

2867 Andreas Haufler and Frank Stähler, Tax Competition in a Simple Model with Heterogeneous Firms: How Larger Markets Reduce Profit Taxes, December 2009

2868 Steinar Holden, Do Choices Affect Preferences? Some Doubts and New Evidence, December 2009

2869 Alberto Asquer, On the many Ways Europeanization Matters: The Implementation of the Water Reform in Italy (1994-2006), December 2009 
2870 Choudhry Tanveer Shehzad and Jakob De Haan, Financial Reform and Banking Crises, December 2009

2871 Annette Alstadsæter and Hans Henrik Sievertsen, The Consumption Value of Higher Education, December 2009

2872 Chris van Klaveren, Bernard van Praag and Henriette Maassen van den Brink, Collective Labor Supply of Native Dutch and Immigrant Households in the Netherlands, December 2009

2873 Burkhard Heer and Alfred Maußner, Computation of Business-Cycle Models with the Generalized Schur Method, December 2009

2874 Carlo Carraro, Enrica De Cian and Massimo Tavoni, Human Capital Formation and Global Warming Mitigation: Evidence from an Integrated Assessment Model, December 2009

2875 André Grimaud, Gilles Lafforgue and Bertrand Magné, Climate Change Mitigation Options and Directed Technical Change: A Decentralized Equilibrium Analysis, December 2009

2876 Angel de la Fuente, A Mixed Splicing Procedure for Economic Time Series, December 2009

2877 Martin Schlotter, Guido Schwerdt and Ludger Woessmann, Econometric Methods for Causal Evaluation of Education Policies and Practices: A Non-Technical Guide, December 2009

2878 Mathias Dolls, Clemens Fuest and Andreas Peichl, Automatic Stabilizers and Economic Crisis: US vs. Europe, December 2009

2879 Tom Karkinsky and Nadine Riedel, Corporate Taxation and the Choice of Patent Location within Multinational Firms, December 2009

2880 Kai A. Konrad, Florian Morath and Wieland Müller, Taxation and Market Power, December 2009

2881 Marko Koethenbuerger and Michael Stimmelmayr, Corporate Taxation and Corporate Governance, December 2009

2882 Gebhard Kirchgässner, The Lost Popularity Function: Are Unemployment and Inflation no longer Relevant for the Behaviour of Germany Voters?, December 2009

2883 Marianna Belloc and Ugo Pagano, Politics-Business Interaction Paths, December 2009

2884 Wolfgang Buchholz, Richard Cornes and Dirk Rübbelke, Existence and Warr Neutrality for Matching Equilibria in a Public Good Economy: An Aggregative Game Approach, December 2009 